\title{
Hypersonic weapons and the future of nuclear deterrence
}

\author{
Eben Coetzee $e^{130}$ \\ Department of Political Studies and Governance, \\ University of the Free State
}

\begin{abstract}
It is widely accepted today that hypersonic weapons pose insurmountable challenges to nuclear deterrence. Although speed has always been a critical factor in warfare, the development of hypersonics provides unprecedented advantages in terms of the speed and agility of missiles. The increase in the speed and agility of hypersonic missiles drastically reduces the response time of nuclear states, encouraging the pre-emptive use of force. Two arguments inform the latter claim. The first holds that the speed and agility of hypersonic missiles are likely to render existing and future missile defences obsolete. The second contends that the failure of missile defences coupled with the reduction of the response time of nuclear states encourages the pre-emptive use of force. Where nuclear states are unable to field survivable second-strike forces, the stability of nuclear deterrence becomes highly problematic. Besides these arguments, the dual-use nature of hypersonic weapons ostensibly increases the risk of nuclear escalation. Against this bleak assessment, in this article, the author questions the destabilising effects of hypersonic weapons on deterrence stability, arguing that nuclear deterrence is - and is likely to remain - deeply stable. A thoroughgoing consideration of the strategic implications of nuclear weapons provides optimism about the stability of nuclear deterrence in the face of the development of hypersonic weapons. Two arguments are advanced in support of the continuing stability of nuclear deterrence. First, missile defences have (and are likely to remain) inefficacious, with the development of hypersonic weapons merely reinforcing (rather than establishing) this fact. Second, a would-be aggressor contemplating the pre-emptive use of force would have to believe that it could destroy all of an adversary's nuclear force before any can be launched.
\end{abstract}

\section{Keywords}

Hypersonic weapons; nuclear deterrence; war; emerging technologies; missile defence

\section{Introduction}

Concerns over the potentially destabilising effects of hypersonic weapons on deterrence stability are mounting. The term 'hypersonic' denotes aircraft, missiles, rockets, and spacecraft capable of travelling through the atmosphere at speeds exceeding 5000 kilometres per hour or Mach 5. ${ }^{131}$ The development of hypersonics is believed to be a game-changer technology. James Miller, the principal advisor to the United States (US) High-Speed Systems Division of the Air Force Research Laboratory (AFRL) at the 
Aerospace Systems Directorate in Ohio, notes that hypersonics provide unprecedented speed for "engaging time-sensitive targets" and ensuring the survivability of systems. ${ }^{132}$ Moreover, weapons and weapon systems capable of operating at hypersonic speeds provide the potential for longer-range military operations with shorter response times and increased effectiveness. ${ }^{133}$

Speed has been and continues to be a critical factor in warfare, a proposition borne out by Germany's blitzkrieg strategy during World War II and, more recently, the US "shock and awe" campaign during the invasion of Iraq in 2003. ${ }^{134}$ Speed, Michael Klare correctly concludes, "is also a significant factor in the nuclear attack and deterrence equation". ${ }^{135}$ The development and deployment of intercontinental ballistic missiles (ICBMs) during the 1950s had reduced the response time of nuclear states to mere minutes. Fears emanating from the reduction of the response time of nuclear states culminated in the deployment by nuclear states of early-warning and command-andcontrol (C2) systems designed to detect a missile launch, and to launch a retaliatory strike before their own arsenal could be destroyed. ${ }^{136}$ Today, the time between the launch of a weapon and the destruction of a target has dwindled to 10 minutes or less. ${ }^{137}$ Hypersonic weapons, accordingly, drastically lessen the response time of nuclear states, with the survivability of nuclear states' second-strike (retaliatory) forces increasingly at risk. Where nuclear states are unable to deploy survivable second-strike forces, deterrence becomes obsolete, and the risk of pre-emption (i.e. to strike weapons before they can be used) becomes very real. The conclusion reached is that hypersonic weapons will undoubtedly pose grave and new threats to deterrence stability. ${ }^{138}$ The death knell for deterrence, it seems, has sounded.

However, by drawing on insights gleaned from the writings of Kenneth Waltz and Bernard Brodie, this analysis contends that fears about the potentially destabilising effects of hypersonic weapons on deterrence stability are misplaced. Consideration and appreciation of the strategic implications of nuclear weapons quickly dispel such fears and powerfully reinforces the notion that nuclear weapons can continue to work their deterrent effects in the face of the rapid development and employment of hypersonic weapons. It is against this backdrop that the current study contends that nuclear deterrence is - and is likely to remain - remarkably efficacious. The structure of the remainder of this article is as follows. I firstly consider the differences between hypersonic glide vehicles and hypersonic cruise missiles, discuss the hypersonic weapons programmes of the United States, Russia and China, and outline the claims and arguments supporting the view that hypersonic weapons will invariably lead to deterrence instability. Next, I discuss the nature and requirements of deterrence and the qualitatively different constraints of deterrence in a conventionally armed, as against a nuclear-armed world, arguing that deterrence is more easily contrived than widely thought. This is followed by consideration of the commonly perceived difficulty of creating invulnerable secondstrike forces. I then show how the destabilising effects ascribed to hypersonic weapons are insufficient to upend deterrence. I conclude with a summary of the main findings and their implications for the future of deterrence stability. 


\section{Hypersonic weapons: types, developments and fears}

It is fair to say that an arms race in hypersonic weapons technology is unfolding before our eyes, with Russia, China and the United States as the principal competitors. ${ }^{139}$ In this highly competitive race, as in others today, the Americans are finding it increasingly difficult to keep up with Russian and Chinese hypersonic developments. ${ }^{140}$ Before we scrutinise the various developments in hypersonic weaponry of each competitor, it will serve our ends well to distinguish between two types of hypersonic weapons. The first type - the hypersonic glide vehicle or, as it is sometimes referred to, the boost-glide weapon - is dependent on a booster rocket that carries the glide vehicle into the outer atmosphere, a process similar to the launch of an ICBM. ${ }^{141}$ Once the glide vehicle reaches an altitude of 64 to 160 kilometres above the earth's surface, the vehicle is released from the booster. ${ }^{142}$ Whereas an ICBM is launched into the atmosphere and, after turning, plummets to the ground, a glide vehicle soars along the outer boundary of the atmosphere (above the range of sensors) before heading towards its target. ${ }^{143}$ These vehicles boast great manoeuvrability during flight (similar to a cruise missile) combined with high speed (exceeding that of an ICBM) and precision-strike ability. ${ }^{144}$ Unlike hypersonic glide vehicles, the second type of hypersonic weapon, namely the hypersonic cruise missile, is restricted to flight within the atmosphere. It can be launched from the sea, air or land. ${ }^{145}$ These weapons are dependent on advanced air-breathing jet engines (for example, scramjets, also known as supersonic combustion ramjets) to reach and exceed Mach 5. However, given that these missiles carry their own fuel, their range is far less than is the case with hypersonic glide vehicles.

Both types of weapons have advantages and limitations. The dependence of hypersonic glide vehicles on rocket boosters suggests two important things: firstly, the technology related to rocket boosters is well established and proven and, secondly, rocket boosters offer both great speed and range. ${ }^{146}$ The US Air Force's (USAF) Minuteman III ICBM, which was taken into service in 1970, has a range of over 9650 kilometres and can reach Mach 23. However, as is widely known, ICBMs lack the ability to steer. After their launch, they travel along a predictable path (much like a cannonball). ${ }^{147}$ What sets boost-glide weaponry apart is their replacement of a traditional warhead with that of an agile glider. Subsequent to the rocket booster burning out, the glide body separates from the booster and, as noted above, glides along the top of the atmosphere to their targets, with the attendant ability to manoeuvre while in flight. ${ }^{148}$ While the advantages are impressive, notable disadvantages prevail. Jeffrey Lewis, a nuclear expert from the Monterey-based Middlebury Institute of International Studies in California, notes that the glide body, once separated from the booster, "will no longer be travelling at hypersonic speeds". ${ }^{149}$ Given that the missile is gliding, it decreases in speed (thus a decrease in re-entry), making it an even greater target than traditional ICBMs for missile defences. ${ }^{150}$ The manoeuvrability of glide vehicles, of course, provides the benefit of evading missile defences, but once the missile enters the range of missile defences, it will be an easier target to intercept than a traditional ICBM. ${ }^{151}$ 
On their part, hypersonic cruise missiles employ air-breathing engines. These engines are much smaller in size than hypersonic glide vehicles (the engine only has to carry the fuel while absorbing all the requisite oxygen from the atmosphere), implying that the entire weapon can be much smaller. The weapon's much smaller scale brings two advantages: firstly, the weapon can be fitted onto aircraft, ships or submarines without much difficulty; and, secondly, instead of merely gliding to the target, rapid acceleration becomes possible during flight; thus, increasing the manoeuvrability of the weapon. ${ }^{152}$ The drawbacks of hypersonic cruise missiles are twofold. The first drawback refers to the complexity and cost of technology associated with the engines powering hypersonic cruise missiles. While the technology associated with conventional jet engines are well established, these engines do not operate at hypersonic speeds, thus pointing towards the necessity of scramjet engines, which are complex and costly to develop. The second drawback relates to the speed at which air-breathing weapons can travel. Given that air-breathing weapons are oxygen-dependent and high altitudes have less oxygen, these weapons fail to reach the extensive altitudes characteristic of boost-glide missiles. This negatively affects the speed of the weapon, with air-breathers likely to reach speeds close to Mach 7, far less than that of a boost-glide weapon. ${ }^{153}$

Russia, China and the United States have all invested substantial resources in developing either or both types of hypersonic weapons, with the United States (as noted above) lagging behind. At the time of writing, the USAF's AGM-138A air-launched rapid response weapon (ARRW), a conventionally armed boost-glide missile, is the only hypersonic weapon likely to enter into service in the near future, with the first fullsystems trial scheduled for October 2021 and flight tests continuing through 2022. ${ }^{154}$ Although the United States is pursuing various hypersonic weapons programmes, a recent Congressional Research Service Report notes that these programmes are in different phases of research, development, testing and evaluation, rather than in the procurement phase. ${ }^{155}$ The sluggish pace of US hypersonic weapons programmes contrasts sharply with those of Russia and China.

Russia has already fielded both hypersonic glide vehicles and hypersonic cruise missiles. The Avangard hypersonic missile is a boost-glide weapon launched from an ICBM, giving the weapon virtually unlimited range. The weapon boasts on-board countermeasures, can carry a nuclear weapon with a two-megaton payload, and can reach speeds of Mach 20. ${ }^{156}$ The Tsyrcon (also spelled Zircon) is a ship-launched hypersonic cruise missile capable of reaching speeds between Mach 6 and Mach 8. ${ }^{157}$ Russia's Project 22350 frigate Admiral Gorshkov successfully launched the missile during January 2020, while a successful test of the missile against a naval target was conducted on 7 October 2020. ${ }^{158}$ The weapon can strike both ground and naval targets, and can be launched from various platforms, including cruisers, corvettes, Project 22350 frigates, and the Project 885 Yasen-class submarines. ${ }^{159}$ In addition to the Avangard and the Tsyrcon, Russia has developed and fielded a nuclear-capable air-launched ballistic missile, the Kh-47M2 Kinzhal hypersonic missile, capable of reaching Mach 10 and with a range above 2000 kilometres. ${ }^{160}$ The missile travels at the stratosphere boundary to reduce air resistance, and is specifically designed to evade enemy air defences. ${ }^{161}$ Although the Kinzhal is neither a hypersonic glide vehicle nor a hypersonic cruise 
missile, it forms part of Russia's hypersonic weapons programmes. ${ }^{162}$ The speed of the weapon and its ability to perform evasive manoeuvres during every phase of its flight pose defensive challenges akin to other hypersonic weapons. Hence, it is worth including it in this discussion. ${ }^{163}$

China's hypersonic weapons programmes have likewise outpaced those of the United States (although lagging behind Russia), with Chinese programmes involving various institutes and boasting considerable investment in facilities pertinent to hypersonic flight development (e.g. wind tunnels developed to simulate flight conditions reaching Mach 25). ${ }^{164}$ It is worth noting that, over the last five years, China has conducted 20 times more hypersonic tests than the United States. ${ }^{165}$ Particularly noteworthy is the DF-17 conventional missile. This medium-range ballistic missile employs a sleek hypersonic glide vehicle and has a range of 1800 to 2500 kilometres. ${ }^{166}$ It is widely argued that the weapon entered service in October 2019. ${ }^{167}$ Moreover, during 2019, China also unveiled the solid-fuelled road- and rail-mobile ICBM, the DF-41, which is capable of carrying either a conventional or nuclear hypersonic glide vehicle. ${ }^{168}$ The weapon can reach Mach 25, and has a range of 12000 to 15000 kilometres; thus, it is capable of reaching the continental United States in less than 30 minutes. ${ }^{169}$ In August 2018, China conducted various successful tests of the nuclear-capable hypersonic vehicle prototype, the Xingkong-2 (Starry Sky-2). The Xingkong-2 - a hypersonic cruise missile - uses a rocket motor to launch it vertically, but then uses its own propulsion system to power the missile after separation. ${ }^{170}$ The vehicle travelled at Mach 6 and is generally referred to as a 'waverider', i.e. a vehicle that uses "powered flight after launch and derives lift from its own shockwaves". ${ }^{171}$ After the launch of the Xingkong-2, China's state-owned newspaper, China Daily, indicated that the powered flight of the missile "lasted for 400 seconds". ${ }^{172}$ In June 2020, China's Institute of Mechanics reported positively on the ground test "of a scramjet engine that ran for 600 seconds", indicating China's rapid progress in developing hypersonic cruise missiles. ${ }^{173}$

Against the backdrop of these developments, nuclear experts generally contend and fret that hypersonic weapons pose insurmountable challenges to deterrence stability. Accordingly, what are the fears? Principally, the increasing agility and speed of hypersonic weapons drastically reduce the response time of nuclear states, emboldening a would-be aggressor to launch a pre-emptive strike. Two arguments inform this particular claim. Firstly, the speed and agility of hypersonic missiles would render existing and future missile defences obsolete. Secondly, the failure of missile defences coupled with the reduction in the response time of nuclear states encourages the preemptive use of force - in short, second-strike forces can be destroyed before they can be employed. ${ }^{174}$ Besides concerns over hypersonic weapons squeezing the response time of nuclear states, nuclear observers further fret that the dual-use nature of hypersonic weapons (i.e. they can carry a nuclear or a conventional warhead) dramatically increases the risk of escalation. ${ }^{175}$ In an often-feared scenario, a would-be aggressor using hypersonic weapons decides to target key enemy assets (e.g. surface ships, submarines, or nuclear command, control, communications, and intelligence [C3I] systems) at the outset of a conflict. Given the dual-use nature of hypersonic weapons, and being unable to discern the intentions of the aggressor, nuclear states are likely to launch their own 
nuclear weapons in the face of a 'use it or lose it' situation. Consideration of the nature and requirements of deterrence and, concomitantly, the ease of creating invulnerable second-strike forces, will go some way in allaying fears about the destabilising effects of hypersonic weapons on deterrence stability.

\section{The nature and requirements of deterrence}

Fretting about the stability of deterrence is as old as the nuclear age itself. Such fears - today and in the past - stem from misunderstanding the nature and requirements of deterrence. Accordingly, in this section the author discusses three aspects related to nuclear deterrence that are often prone to misunderstanding:

- the fundamental differences between international politics conducted in a conventionally armed world as against a nuclear-armed world;

- $\quad$ the question of what is required to deter; and finally

- $\quad$ the widely held belief that leaders must be rational for deterrence to work its effects.

The ostensible challenge of creating invulnerable second-strike forces is discussed in the next section.

\section{Conventional versus nuclear deterrence}

States dissuade one another from attacking by employing one of two strategies. The first strategy, generally called the defensive ideal, is geared towards building forbiddingly strong forces and fortifications that look well-near impregnable to the attacker. ${ }^{176}$ In this strategy, the emphasis is placed on reducing the capability of the enemy to inflict damage. ${ }^{177}$ On the other hand, a strategy of deterrence turns on building retaliatory forces capable of inflicting unacceptable punishment on a state wishing to attack its manifestly vital interests. ${ }^{178}$ 'To deter' means to dissuade someone from a certain course of action by frightening such person with unacceptable consequences. Although the two strategies work toward the common aim of dissuading a wouldbe aggressor from attacking, they each employ distinctive means to reach this aim. Accordingly, purely deterrent forces promise no ability to defend; conversely, purely defensive forces present no ability to punish. Each strategy conveys a different message to a would-be aggressor. The message of a strategy based on defence is this, 'although we are without ability to strike back at you, our defences are so impregnable that any attempt to overcome them would yield cost and risk far outweighing any prospective gain'. ${ }^{179}$ Conversely, a strategy based on deterrence conveys the message, 'although we are without ability to defend, if you attack, we will punish you in ways that bring more pain than gain, more cost than reward'. A deterrent strategy is not geared to fending off an aggressor, but to destroying or damaging the manifestly vital interests of an aggressor. ${ }^{180}$ Such a strategy is well served by second-strike nuclear forces. In deterring an aggressor, one thus needs nothing more than a force capable of surviving a first strike and striking back sufficiently hard to cancel any gains an aggressor might wish to obtain. ${ }^{181}$ 
The credibility of deterrent threats in a conventionally armed world is extraordinarily difficult to establish. Would-be aggressors might chance their luck believing that the outcome of battle is dependent on many factors (some of which are within their control), and that the consequences of their aggression might not be so severe. They may believe that the weapons, strategy and sheer determination of their armed forces will carry the day and that their suffering, should defeat come, will be limited. As history has shown, predicting the outcomes of conventional wars has proved to be inordinately difficult. ${ }^{182}$ In a conventional world, uncertainty about outcomes does little to restrain states from fighting wars. ${ }^{183}$ Miscalculation, a major cause of war, becomes all the more likely in a conventional world because states at once overestimate their own position and believe that their suffering might be limited in the face of defeat.

A nuclear world invokes a distinctive kind of reasoning. Calculations about nuclear war proceed along different lines than those found in a conventional world. ${ }^{184}$ Two or more nuclear-armed states contemplating war do so full well knowing that their suffering, should war ensue, may be unlimited. That it might turn out not to be the case is, of course, true, but it is hardly the kind of uncertainty that encourages the use of force. ${ }^{185}$ In a conventional world, given difficulties in gauging the military capabilities of competitors, uncertainty constrains one to think in terms of winning or losing. In a nuclear world, uncertainty constrains states to think in terms of survival or annihilation. ${ }^{186}$ As Soviet premier, Nikita Khrushchev, famously remarked in June 1964, "[n]uclear war is stupid, stupid, stupid! If you reach for the push button you reach for suicide." ${ }^{187}$ Apart from sheer survival, nuclear war can serve no other political goal. ${ }^{188}$

The destructiveness promised by the outcome of a nuclear exchange breaks sharply from the uncertainty in predicting outcomes in a conventional world. This, as Kenneth Waltz aptly notes, makes one wonder about the oft-heard charges that deterrence depends on perceptions, and that the credibility of deterrent threats is difficult to establish. ${ }^{189}$ As noted above, the uncertainty in predicting outcomes in a conventional world emboldens leaders to risk war. On the other hand, imagining the catastrophe promised by nuclear wars constrains leaders to step back from the brink of war. ${ }^{190}$ Everyone - from the leaders of states to the man in the street - knows that catastrophe lies at the door should things get out of hand and nuclear weapons go off. ${ }^{191}$ Making that prediction is fairly simple, given that it is not dependent on a close estimate of opposing forces. The number of cities vulnerable to the attacks by an adversary equals the number of strategic warheads it can deliver. Yet, within wide ranges, variations of number matter little. For, as Kenneth Waltz explains, "[ $t]$ he expected effect of the deterrent achieves an easy clarity because wide margins of error in estimates of the damage one may suffer do not matter." 192 Will we lose one or two, two or three, or five or ten cities? When these are the questions vexing our minds, we cease thinking about running risks and start fretting about how best to avoid them. ${ }^{193}$ Given that catastrophe looms in the face of the use of nuclear weapons, these weapons "create their own credibility". ${ }^{194}$ The problems and uncertainties that plague the effectiveness of deterrent threats in a conventional world - i.e. the distant, limited and problematic nature of the damage threatened - quickly disappear in a nuclear one. Nuclear weapons at once remove the vexing problem of military miscalculation and make politically pertinent prediction possible. ${ }^{195}$ 
The credibility of deterrent threats in a nuclear world derives from the particular qualities of nuclear weapons and the effects they produce. As the title of a book edited by Bernard Brodie fittingly suggests, nuclear weapons constitute The absolute weapon. ${ }^{196}$ Nuclear weapons can work their deterrent effects irrespective of what other countries do. If a nuclear state were able to wipe out all of the strategic warheads of an adversary, or to defend against 'the bomb' such that only a few warheads slip through, Brodie's title would be seriously misleading. ${ }^{197}$ However, nuclear weapons are absolute in nature, with four interrelated qualities accounting for this feat:

- nuclear weapons are terribly destructive yet small in size;

- not only are they more destructive than anything produced before, but the speed at which destruction occurs is unprecedented. As Thomas Schelling aptly noted, "[t]o compress a catastrophic war within the span of time a man can stay awake drastically changes the politics of war"; ${ }^{198}$

- $\quad$ rendering a sufficient number of warheads invulnerable to attack is a fairly easy endeavour; and

- there exists no adequate defence against the bomb (today and for the foreseeable future), such that delivering a sufficiently large number of warheads is impossible to thwart. ${ }^{199}$

The last point above implies that a state subjected to a retaliatory strike is defenceless, with the amount of damage inflicted upon it dependent on the attacker's restraint and little on any efforts it can muster. ${ }^{200}$

\section{What is required to deter?}

Is deterrence difficult to contrive? The short answer is 'no'. Deterring an adversary requires the ability to inflict unacceptable damage on an aggressor. During an interview with Anna Cornelia Beyer, Kenneth Waltz aptly noted that 'unacceptable damage' is often mistakenly defined as the ability to destroy much, if not most, of an adversary's country. ${ }^{201}$ For former US Secretary of Defence, Robert McNamara, this meant that the United States needed to destroy nearly $20-25 \%$ of the population of the Soviet Union and, concerning its industrial capacity, about 50-66\%. Estimations of what is required to deter are often inordinately high. To deter an adversary, one needs not appear to have the ability to destroy $50 \%$ or even $25 \%$ of another country. Would South Korea attempt to destroy North Korea's nuclear weapons at the risk of one 100-kiloton nuclear weapon exploding above Busan, a South Korean port city? According to estimations from the modelling tool NUKEMAP, such a detonation would kill 440000 people in seconds, a figure referring only to fatalities from the immediate blast. ${ }^{202}$

The belief that deterrence depends on destroying cities and, concurrently, that a strategy of deterrence must be wedded to the threat of massive retaliation, is a false one. Destroying a country is not necessary for deterrence to work. States are deterred not because of the expectation that they will suffer a certain amount of damage, but because they have no way of knowing how much damage they will suffer. ${ }^{203}$ Deterrence is based on what one country can do to another country, not on what it will do. What is required 
to deter is the ability or, importantly, the appearance of the ability that an attack by an aggressor will be met with a retaliatory blow incurring a high degree of damage. It matters little whether or not you can retaliate, as long as the aggressor state believes that you have the ability to do so. ${ }^{204}$ As Bernard Brodie puts it, "[ $\left.\mathrm{t}\right]$ he threat of retaliation does not have to be 100 percent certain; it is sufficient if there is a good chance for it [...] The prediction is more important than the fact." ${ }^{205}$ To put it differently, states in a conventional world could initiate war if they believed the possibility of success to be high; in a nuclear world, aggression is stymied where the aggressor believes retaliation is possible. What is required to deter is not certainty but uncertainty of response because, if retaliation occurs, an aggressor stands to lose so much. ${ }^{206}$ In a conventional world, uncertainty tempts states to initiate war; in a nuclear world, it produces hesitation, because the consequences of action are too dangerous to bear. ${ }^{207}$

\section{Leaders, rationality and deterrence}

Nuclear weapons deter aggression against the manifestly vital interests of their possessors, irrespective of the identity of rulers or the characteristics of their states. ${ }^{208}$ However, we are often told that the cognitive abilities of leaders (especially those of new and prospective nuclear states) are a cause for concern. These leaders, so the argument goes, might be slow to learn and appreciate the constraining effects of nuclear weapons. ${ }^{209}$ Internally, such leaders might prove to be ruthless and radical, espousing revolution at home and abroad. Observers of nuclear affairs then fret that the external behaviour of these states might match their internal aggression. Yet, the history of international politics illustrates that international political outcomes are not uniquely determined by the internal characteristics of states and the particular qualities of their leaders. ${ }^{210}$ External pressures constrain the behaviour of states, with the force of the pressure varying with conditions. ${ }^{211}$ Of all the external forces impinging upon states, what could exert a greater effect on state behaviour than nuclear weapons? The cognitive abilities of leaders matter little when everyone but an idiot can appreciate their destructive force. ${ }^{212}$ When confronted with such clear and present danger, what more do leaders need to learn, and how is it conceivable that they can miscalculate? To launch a first strike in the absence of a guarantee of success and, simultaneously, the presence of the promise of retaliation, implies that all those who wield control over nuclear decisionmaking would have to become insane at once. Accordingly, Joseph Nye notes that nuclear weapons produce the "crystal ball" effect, i.e. it is evident to everyone around that catastrophe lies around the corner if force gets out of hand. In a conventionally armed world, the crystal ball's outlook is cloudy; in a nuclear-armed world, the outlook is "perfectly clear". ${ }^{213}$ The reality of a nuclear world trumps political rhetoric. ${ }^{214}$ Nuclear weapons constrain their possessors - all of them - to act with caution. ${ }^{215}$

One of the hackneyed criticisms levelled against nuclear deterrence is the charge that it assumes leaders to be rational. ${ }^{216}$ The efficacy of deterrence, according to this view, rests on rationality. ${ }^{217}$ As Tom Sauer and Ramesh Thakur (amongst a host of others) recently reiterated, "deterrence stability depends on rational decision-makers being always in office in every single nuclear-armed country. The leaders of the nine countries with the bomb today [...] do not universally reassure on this score" [my emphasis]. ${ }^{218}$ 
Critics correctly note that individuals are not "necessarily utility-maximizing machines that rationally purse material gain and expect others to do the same". ${ }^{219}$ However, as Kenneth Waltz notes, "deterrence does not rest on rationality, whatever that term might mean" [my emphasis]. ${ }^{220}$ Defined simply, a person is rational if he or she is able to reason. It does not take much reasoning to conclude that fighting nuclear wars is impossible, and to launch a path of aggression in the face of retaliation "is obvious folly". ${ }^{221}$ In drawing those conclusions, one does not need to engage in complicated calculations, but only needs to apply a little common sense..$^{222}$

Robert Jervis agrees and notes, "even an emotional, short-sighted, and dim-witted opponent" would be able to see clearly that aggression against a nuclear opponent would be the "worst alternative". ${ }^{223}$ Moreover, as Jervis further argues, rationality is neither a necessary nor a sufficient condition for deterrence, and for two good reasons. ${ }^{224}$ Firstly, critics usually associate irrationality with a leader marked by emotional impulsiveness bent on launching an attack or someone prone to risk-taking. Yet, irrationality could have the opposite effect, leading a state to acquiesce passively, while a rational take on the situation could embolden a state to act with aggression. Secondly, a wouldbe aggressor is less likely to launch a first strike if it fears its adversary will retaliate without properly assessing the risks. ${ }^{225}$ Deterrence is not dependent on rationality, but on fear - and nuclear weapons provide the best of all possible means to create fear. ${ }^{226}$

A related criticism is that the efficacy of deterrence rests on all parties accepting the 'doctrine' of deterrence. During the Cold War (1947-1991), nuclear observers were concerned that deterrence would fail if the Soviet Union did not accept the doctrine.227 Thus, Henry Kissinger lamented that the 'theory' of mutual assured destruction (MAD) was weakened because the Soviets did not believe it. ${ }^{228}$ However, as Waltz notes, the "efficacy of deterrence" is not dependent on "anyone accepting it". ${ }^{229}$ Today, as before, nuclear observers worry that the values, perceptions and calculations of nuclear adversaries may diverge and, where they do, nuclear disasters loom. When he was Secretary of Defence, Harold Brown warned that the only way to quell the Soviet Union's drive for and use of "war-winning capabilities" was to ensure that "the Soviets will clearly understand that we will never allow them to use their nuclear forces to achieve any aggressive aim at an acceptable cost" ${ }^{230}$ Now, faced with the rambunctious North Korean leader, Kim Jong Un, nuclear observers emphasise that Washington must understand not only North Korea's objectives, but also "how North Korean officials understand U.S. objectives and whether they consider U.S. statements credible". ${ }^{231}$ One wonders, however, what more the Soviets then, and North Korean officials now, need to understand when the dangers are so clear and the consequences so easily imagined. Today, as before, not much need to be understood or accepted by leaders to appreciate the destruction a few nuclear weapons can bring.

\section{Creating invulnerable second-strike forces}

Creating credible second-strike forces is less daunting than most observers believe. Nuclear weapons are light, easy to move and to hide, and their means of delivery are easily devised and procured. In fact, their means of delivery are as wide-ranging as 
the ingenuity of their possessors. Beyond the traditional delivery vehicles (consisting of ICBMs, ballistic missile submarines, and strategic aircraft), nuclear weapons can be delivered by trucks driven in from neighbouring states or by small boats firing torpedoes while lying offshore. They can also be placed in small packages in cargo ships and detonated upon receiving a signal, and, yes, they can also be delivered by oxcart. Nuclear states, moreover, may deploy real weapons alongside dummies, while leading other states to believe that the arsenal of such nuclear state is much larger than it actually is. ${ }^{232}$

Moreover, and again, contrary to popular belief, the idea that a credible secondstrike force requires large numbers is a false one. A few strategic warheads - deliverable and of uncertain location - are sufficient for creating a second-strike force. ${ }^{233}$ Yet, we often wonder whether the credibility of retaliatory threats would hold if the strategic forces of the aggressor outnumber those of the attacked. In a conventional war between two nuclear-armed states, will an unsuccessful defender have the resolve to use its retaliatory force first against an aggressor with superior strategic forces? This question is entirely misplaced, for a would-be aggressor would concern itself less with the strategic balance of nuclear forces and more with whether its aggression would cause nuclear weapons to rain down on it. ${ }^{234}$ Two or more nuclear states encroaching on each other's manifestly vital interests are constrained to act with moderation because the immoderate behaviour of each state increases the credibility of the other's nuclear threats. In considering deterrent forces, what matters is not the numerical superiority of one state vis-à-vis the rest, but whether a state is capable of striking back and causing unacceptable damage. The numerical superiority or inferiority of states' strategic forces has no effect on how each state calculates danger or on the question of whose resolve is the greatest. ${ }^{235}$ With this in mind, retaliatory forces are best seen in absolute instead of relative terms. ${ }^{236}$

Small nuclear forces can deter larger ones, as the history of the nuclear age illustrates. Justin Galen (pseudonym), writing in 1979, wondered whether the Chinese 60-80 medium-range and 60-80 intermediate-range missiles (both of which were of doubtful accuracy and reliability) and their obsolete bombers were sufficient to deter the Soviet Union. ${ }^{237}$ The missiles, even if fired at cities, were likely to miss their targets, and the bombers were likely to be overwhelmed by Soviet Union defences. The Soviets, moreover, were likely able to launch a pre-emptive attack, having "almost certainly located virtually every Chinese missile, aircraft, weapons storage area and production facility". ${ }^{238}$ The Soviet leaders, however, surely saw things in a different light. Locating well-near all missiles and aircraft is insufficient. The point - for them and now for us - is that some Chinese missiles and some bombers might have slipped through. ${ }^{239}$ The Cuban Missile Crisis of 1962 further illustrates the point. Reflecting on the crisis years later, Henry Kissinger noted that the Soviet Union had only about "60-70 truly strategic weapons" compared to roughly 2000 American missiles and bombs. ${ }^{240}$ Yet, as he concluded, "with some proportion of Soviet delivery vehicles surviving, the Soviet Union could do horrendous damage to the United States". ${ }^{241}$ In assessing their strike capabilities during the crisis, the US Tactical Air Command claimed that it could destroy $90 \%$ of the Soviet missiles placed in Cuba. The damage promised by the remaining 
$10 \%$ - some six to seven missiles - was deemed unacceptable to the United States. ${ }^{242}$ In essence, the United States could not be confident that its 2000 strategic warheads would destroy the Soviet Union's 60 or $70 .{ }^{243}$ Absent the guarantee that the United States could destroy all of the Soviet Union's strategic warheads (or, for that matter, Soviet bombers, launchers or submarines), who would run the risk? ${ }^{244}$

The above illustrations powerfully underline two basic truths about nuclear weapons, both of which are pertinent to the purported destabilising effects of hypersonics on deterrence stability. Firstly, not much is needed to deter. A small force may indeed be more vulnerable than a bigger one, but it is only worse than a bigger one if an "attacker believes he can destroy all of the force before any of it can be launched" [emphasis in original]. ${ }^{245}$ Lacking this belief, a small second-strike force becomes equivalent to a large second-strike force. ${ }^{246}$ Secondly, if any part of a nuclear force is invulnerable, the entire force is rendered invulnerable. ${ }^{247}$ It does no good if a major part of a nuclear force can be destroyed when a small number of surviving warheads could cause such great damage. With conventional weapons, a premium is placed on the ability to launch a debilitating first strike, thereby getting the upper hand and setting the course of the war. In essence, the first phase of war becomes of overriding importance in a conventionally armed world. With nuclear weapons, striking first scarcely matters if it risks the destruction of a number of cities. What matters most is not the first stage of war but what happens at the end of the war. ${ }^{248}$ "Uncertainty about controlling escalation", Kenneth Waltz reminds us, "lies at the heart of deterrence." 249 This reality was aptly conveyed by President Kennedy during the Cuban Missile Crisis of 1962, “[i]t isn't the first step that concerns me, but both sides escalating to the fourth and fifth step - and we don't go the sixth because there is no one around to do so." ${ }^{250}$

\section{Hypersonic weapons and deterrence instability?}

Nuclear deterrence remains deeply stable, notwithstanding the impressive and rapid development of hypersonic weapons. As the reader will recall, nuclear experts are concerned that the increased agility and speed of hypersonic missiles reduces the response time of nuclear states; thus, encouraging the pre-emptive use of nuclear weapons. This fear is supported by two arguments. Firstly, the speed and agility of hypersonic missiles would render missile defences obsolete. Secondly, the failure of missile defences coupled with the reduction of the response time of nuclear states encourages the pre-emptive use of force. In short, second-strike forces can be destroyed before they can be employed. Besides this, the dual-use nature of hypersonic weapons ostensibly provides unique escalatory dangers for nuclear war. The conclusion reached by nuclear experts and policymakers is that hypersonic weapons are likely to upend strategic stability.

I first consider the challenge raised by hypersonic weapons to missile defences, then consider the possibility of the pre-emptive use of nuclear weapons and, finally, reflect on how the dual-use nature of hypersonic weapons ostensibly poses insurmountable challenges to nuclear deterrence. 
Fretting about the invulnerability of hypersonic weapons to missile defences is senseless. We have always known, yet very few have apparently appreciated, that the big problem with missile defences is that they do not and will not work. ${ }^{251}$ Most experts agree that a leak-proof defence is impossible, and even if it were possible, there is every reason to doubt that it would not last. ${ }^{252}$ The problem with missile defences was well captured by US President Donald Trump's Secretary of State, Mike Pompeo. When asked why US-deployed Patriot air defence missiles in Saudi Arabia failed to shoot down a barrage of missiles (or perhaps drones) that struck the Abqaiq oil processing centre on 14 September 2019, he replied, "[e]ven the best air defence systems sometimes fail." 253

Confidence in missile defence systems is and has always been misplaced. In October 1964, Soviet leader Nikita Khrushchev lauded Soviet defences by boasting that it had a new missile capable of hitting "a fly in the sky" ${ }^{254}$ However, hitting a fly in the sky solves nothing. The difficulty, Kenneth Waltz presciently notes, lies in hitting many flies in the sky after first "separating the flies from the fleas". ${ }^{255}$ Both the would-be aggressor and the attacked will understand and believe that some warheads would slip through the defences. For missile defences to work they would have to be the most intricate systems ever deployed and they need to work with near perfection when confronted with the only test that matters, i.e. that of enemy fire. ${ }^{256}$

The efficacy of missile defences is further upended by the ease by which they can be thwarted. One way to achieve this is simply to multiply warheads; thus, overwhelming a system with more delivery vehicles than it can handle. ${ }^{257}$ During November 2020, the US Navy destroyer, USN John Finn, conducted a successful intercept test of an ICBM target using the Aegis Ballistic Missile Defense (BMD) system. ${ }^{258}$ Although the successful test was met with much fanfare, the harsh reality is that not much was achieved. As expected, critics have correctly warned that the increase in US reliance on BMD "could spur Russia and China to enhance the size and capability of their nuclear arsenal". ${ }^{259}$ In fact, both Russia (through its hypersonic weapons programme and the development of an undersea torpedo) and China (through diversifying its nuclear strike capabilities) have already responded to US missile defence by ramping up their nuclear delivery options. ${ }^{260}$ Today, as before, multiplying warheads in the face of increasing reliance on missile defences is sufficient to ensure that a few warheads could slip through. The conclusion reached by Daryl G. Kimball is instructive:

Nuclear strategists have long understood that the development and deployment of strategic missile interceptors are ineffective against determined nuclear-armed adversaries but could lead them nonetheless to build more numerous and sophisticated offensive missile systems to overwhelm and evade missile defences. ${ }^{261}$

Besides increasing the number of warheads, other ways to thwart missile defences abound, namely:

- mounting decoys on missiles to spread chaff, thereby confusing the defence;

- launching missiles on depressed trajectories; 
- $\quad$ using inflatable balloon decoys to swamp missile defence systems, rendering them useless; or, if all else fails

- the possibility of carrying bombs in suitcases or launching nuclear warheads from cargo ships lying off-shore remains. ${ }^{262}$

Additionally, we know that cruise missiles have proved to be particularly bothersome for missile defence systems. ${ }^{263}$ Today, as before, multiple ways exist to thwart missile defences and to place warheads on targets. This is not likely to change in the future. The more states build and field missile defence systems, the more others will be emboldened to thwart them.

In fact, US missile defence plans have antagonised Moscow for decades, forcing it to consider ways to offset Washington's apparent strategic advantage. ${ }^{264}$ One of these ways was to invest heavily in the development of hypersonic weapons. Putin's response upon unveiling six new weapons systems during 2018, all of which reportedly renders US missile defences ineffective, is instructive, "[t]hey kept ignoring us." 265 The United States, nonetheless, continues to invest heavily in missile defence systems, ranging from attempts to offset US weaknesses against supersonic cruise missiles to intercepting ballistic missiles outside the atmosphere. ${ }^{266}$ Any gains resulting from such investments are bound to be fraught with the same limitations as previous missile systems and all the more so following the emergence of hypersonic weapons. That hypersonic weapons are invulnerable to missile defences is, accordingly, unproblematic, since missile defences have never been worth their weight in gold to begin with. Today there is still no adequate defence against 'the bomb'.

The second argument informing this claim, to wit, that the failure of missile defences coupled with the reduction of the response time of nuclear states encourage the pre-emptive use of force, is equally misplaced. While it is true that hypersonic missiles will lessen the response time of nuclear states, the militarily important question to ask is whether this will matter. In a conventional world, changes in military technology affect the calculations by states of the relative strength of their adversaries. ${ }^{267}$ With the speed of technological innovation changing rapidly from the late nineteenth century onwards, difficulties in gauging the relative strength of adversaries and in predicting the outcomes of military campaigns multiplied. In the post-1945 world, the speed of technological innovation has become increasingly faster. However, save a breakthrough in missile defence, this scarcely matters. ${ }^{268}$ As JR Wilson aptly points out, it is "hard to do something efficiently with a hypersonic [weapon], where nukes can be delivered by oxcart". 269

During the Cold War, rapid technological innovation did little to alter the US-Soviet military balance, given that improvements in missiles on one side did not imply the obsolescence of missiles on the other side. Whereas the British Dreadnought left other competitors behind in 1906 owing to qualitative improvements in the range and firepower of its guns, this is not the case with missiles. Bernard Brodie famously remarked, "[w] eapons that do not have to fight their like do not become useless because of the advent of newer and superior types." ${ }^{270}$ These weapons do have to survive, but this is a far less 
intractable problem. ${ }^{271}$ Given that a leak-proof defence is impossible to construct, a would-be aggressor contemplating the use of hypersonic missiles (or, for that matter, any other missile) would have to believe that it can destroy all of an adversary's nuclear force before any can be launched. As the reader will recall, during the Cuban Missile Crisis, the US Tactical Air Command claimed that it could destroy $90 \%$ of the Soviet missiles placed in Cuba, an impressively high number. Yet, the damage promised by the remaining $10 \%$ (effectively, some six to seven missiles) was deemed unacceptable to the United States. Accordingly, if any part of a nuclear force is invulnerable, the entire force is rendered invulnerable. With a small number of nuclear warheads able to do such great damage, who would run the risk? In a nuclear world, where uncertainty of response reigns, all parties are similarly constrained to act cautiously. As is often the case, the overwhelming emphasis is placed on the retaliator's difficulties in constructing credible second-strike forces (a problem, as argued above, not overly difficult to solve), while downplaying the aggressor's obvious risks.

Worrying about the effects of hypersonic weapons on the response time of nuclear states is closely related to the (old) question of whether deterrence depends on distance. As Waltz correctly notes, proximity does indeed lessen warning and response time. ${ }^{272}$ Today, such concerns are voiced in the context of India and Pakistan, two contiguous nuclear states, where the missiles of either side could reach the capital of the other in less than five minutes. ${ }^{273}$ More than anywhere else, the possibility of pre-emption apparently looms large here. Where early warning and response times are short, one would presume that decisions about the use of nuclear weapons need to be made quickly. The danger, of course, is that early warning systems could yield false alarms, thereby increasing the prospect of accidental war or, more importantly here, a would-be aggressor might chance its arm, believing it could destroy the nuclear forces of its adversary before the latter can retaliate. Today, as during the Cold War, the idea that deterrence requires the threat of swift retaliation remains deeply engrained in, especially, American and Russian nuclear thinking. However, what deters a would-be aggressor is not the belief that retaliation would be swift, but that in due course retaliation may occur. Retaliation, as K Subrahmanyam reminds us, "need not be highly time-critical". ${ }^{274}$ Where some part of a nuclear force remains invulnerable, questions over the importance of the response time of nuclear states become insignificant. Nuclear states can respond at their leisure, and both the attacker and the attacked will know this. Thus, the spectre of pre-emption owing to the development of hypersonic weapons (and, concurrently, the poverty of missile defence) holds little water where some part of a nuclear force remains invulnerable.

However, what about the oft-cited fear that the dual-use nature of hypersonic weapons provides a dangerous pathway for nuclear escalation? Nuclear experts fear that a would-be aggressor's strike on key enemy assets using conventionally armed hypersonic weapons could be mistaken for a nuclear strike; hence, inclining the leaders of a nuclear state to unleash their own nuclear arsenal in a 'use it or lose it' situation. This, however, surely puts the problem the wrong way around, emphasising the difficulties the deterrer has in gauging the intensions of a would-be aggressor while downplaying the obvious risks run by the deterred. A would-be aggressor who contemplates launching 
a debilitating first-strike on the key enemy assets of an adversary, whether through conventional or nuclear means, cannot otherwise know that such bold action is fraught with dangers. In such a situation, an aggressor has no way of knowing how the attacked would respond. As variously argued, what is required to deter in a nuclear as against a conventional world is not certainty but uncertainty of response because, if retaliation occurs, an aggressor stands to lose so much. Two or more nuclear states encroaching on the manifestly vital interests of the other are constrained to act with moderation because the immoderate behaviour of either state increases the credibility of the nuclear threats made by the other. Nuclear weapons, accordingly, bring moderation and caution all around.

\section{Conclusion}

It is widely argued (and feared) today that the development of hypersonic weapons poses insurmountable challenges to nuclear deterrence. The gist of the concern over hypersonic weapons on deterrence stability is that these weapons are bound to squeeze nuclear states' response time, encouraging the pre-emptive use of force. This claim stems from two arguments: firstly, the speed and agility of hypersonic missiles would render existing and future missile defences obsolete; and secondly, the failure of missile defences coupled with the reduction of the response time of nuclear states encourages the pre-emptive use of force - in short, second-strike forces can be destroyed before they can be employed. Against this bleak assessment, a thoroughgoing appreciation of the strategic effects of nuclear weapons leads to optimism that nuclear weapons can continue to work their deterrent effects in the face of the development and employment of hypersonic weapons.

The first argument undergirding the claim that hypersonic weapons pose insurmountable challenges to deterrence stability, to wit, the vulnerability of missile defences to hypersonic weapons, is baseless. Worrying about the invulnerability of hypersonic weapons to missile defences is senseless. We have always known, yet very few have apparently appreciated, that the big problem with missile defences is that they are highly inefficacious. Hypersonic weapons merely amplify a debilitating problem that existed ever since the development of missile defence systems, namely that constructing a leak-proof defence is impossible. The second argument informing this claim - that the failure of missile defences coupled with the reduction of the response time of nuclear states encourages the pre-emptive use of force - appears to be a more serious one. This latter claim is, however, equally misplaced. While it is, of course, true that hypersonic missiles will lessen the response time of nuclear states, the militarily important question to ask is whether this will matter. The short yet resounding answer is 'no'. Given the difficulties of constructing a leak-proof defence and the ease of creating invulnerable second-strike forces, a would-be aggressor contemplating the use of hypersonic missiles (or, for that matter, any other missile) would have to believe that it can destroy all of an adversary's nuclear force before any can be launched. The threat of retaliation, as Bernard Brodie has noted, need not be $100 \%$ certain. If some chance remains that a nuclear state might retaliate, deterrence will work. What matters most is what one nuclear state appears to be able to do to another (and not what it will 
do), with the prediction of retaliation being more important than the fact. In a nuclear world, uncertainty of response strengthens deterrence. The poverty of missile defence systems and, concomitantly, the reduction in the response time of nuclear states, provide no grounds for believing that nuclear deterrence could not continue to work its effects.

While hypersonic weapons hardly pose insurmountable challenges for nuclear states and, by implication, nuclear deterrence, which challenges, if any, do these weapons pose for the militaries of technologically less-advanced states, those relying primarily on conventional (non-nuclear) means to fend off aggressors? Here a word on the possibly deleterious effects of hypersonic weapons on the future African battlespace might be of value. The increased speed, agility and range of hypersonic weapons, coupled with their invulnerability to missile defence, do not pose unprecedented challenges to African militaries. Why not? For one thing, all states have historically experienced that it is almost impossible to construct a leak-proof defence, a problem that is only compounded by the development of hypersonic weapons. Moreover, the increased speed, agility and range of hypersonic weapons do not provide additional military capability to those states wielding them. Advanced militaries can easily strike sensitive or time-critical targets within African states with weapons other than hypersonic weapons. In more ways than one, the hype of the deleterious effects of hypersonic weapons is overblown. 


\section{ENDNOTES}

${ }^{130}$ Dr Eben Coetzee lectures in the Department of Political Studies and Governance, University of the Free State. His research interests include nuclear deterrence, nuclear weapons, nuclear proliferation, nuclear terrorism and issues of war and peace. The author would like to thank his wife for her unwavering support as well as the Scientia Militaria referees for their invaluable insights.

${ }^{131}$ JR Wilson. "The emerging world of hypersonic weapons technology". Military \& Aerospace Electronics 30/5. 2019. 14-23.

${ }^{132}$ Ibid., p. 17.

133 Ibid.

${ }^{134}$ MT Klare. “An 'arms race in speed': Hypersonic weapons and the changing calculus of battle". Arms Control Today. June 2019. <https://www.armscontrol.org/act/2019-06/ features/arms-race-speed-hypersonic-weapons-changing-calculus-battle $>$ Accessed on 2 July 2019.

${ }^{135}$ Ibid.

${ }^{136}$ Ibid.

${ }^{137}$ Ibid.

${ }^{138} \mathrm{Cf}$. for instance ibid.; MT Klare. "The challenges of emerging technologies". Arms Control Today. December 2018. <https://www.armscontrol.org/act/2018-12/features/ challenges-emerging-technologies $>$ Accessed on 26 August 2019; E Watkins \& T Schroeder. "A direct threat to the US Military: China's new hypersonic weapons". The National Interest. 15 October 2019. $<$ https://nationalinterest.org/blog/buzz/directthreat-us-military-chinas-new-hypersonic-weapons-88356> Accessed on 16 October 2019; AF Krepinevich. "The eroding balance of terror: The decline of deterrence". Foreign Affairs 98/1. 2019. 62-74; M Gault. "Russia's new nuclear missiles squeeze response time". Scientific American. 27 March 2019. <https://www.scientificamerican. com/article/russias-new-nuclear-missiles-squeeze-response-time/?redirect=1> Accessed on 28 March 2019.

${ }^{139}$ C Cordell. "Here comes the boom: Missile defense is becoming big business again".

Washington Business Journal. 17 October 2019. <https://www.bizjournals.com/ washington/news/2019/10/17/missile-defense-is-becoming-big-business-again-and.

${ }^{140}$ Wilson op. cit. html $>$ Accessed on 17 October 2019.

${ }^{141}$ Klare, “An 'arms race in speed' ..." op. cit.

${ }^{142}$ Gault op. cit.

${ }^{143}$ Ibid.; Klare, “An 'arms race in speed' ...” op. cit.

${ }^{144}$ Gault op. cit.

${ }^{145}$ Klare, “An 'arms race in speed'...” op. cit.

${ }^{146}$ SJ Freedberg. "Hypersonics: DoD wants 'hundreds of weapons' ASAP”. Breaking Defense. 24 April 2020. <https://breakingdefense.com/2020/04/hypersonics-dod-wants-hundredsof-weapons-asap/> Accessed on 13 June 2020.

${ }^{147}$ Ibid.

${ }^{148}$ Ibid.; KM Sayler \& A Woolf. "Defense primer: Hypersonic boost-glide weapons". Congressional Research Service. 13 March 2020. <https://fas.org/sgp/crs/natsec/ IF11459.pdf $>$ Accessed on 1 October 2020.

${ }^{149}$ Gault op. cit.

${ }^{150}$ Ibid.; Freedberg op. cit.

${ }^{151}$ Gault op. cit. 
${ }^{152}$ Freedberg op. cit.

${ }^{153}$ Ibid.

${ }^{154}$ D Donald. "Final captive test for US Air Force's hypersonic weapon". AINonline. 10 August 2020. <https://www.ainonline.com/aviation-news/defense/2020-08-10/final-captivetest-us-air-forces-hypersonic-weapon> Accessed on 11 August 2020.

${ }^{155}$ KM Sayler. "Hypersonic weapons: Background and issues for Congress". Congressional Research Service. 27 August 2020. <https://fas.org/sgp/crs/weapons/R45811.pdf> Accessed on 1 October 2020.

${ }^{156}$ Ibid.; J Marcus. "Russia deploys Avangard hypersonic missile system". BBC. 27 December 2019. <https://www.bbc.com/news/world-europe-50927648> Accessed on 12 April 2020.

${ }^{157}$ Sayler op. cit.

${ }^{158}$ T Ripley. "Russian frigate fires hypersonic missile". Janes Navy International 125/3. 2020. 5; S Cranny-Evans. "Russia tests Zircon against naval target". Janes Navy International 125/9. 2020. 6.

${ }^{159}$ Sayler op. cit.; N Novichkov. "Russia launches third Project 22350 frigate". Janes Defence Weekly 23/57. 2020. 7.

${ }^{160} \mathrm{R}$ McDermott. "Russia's aerospace forces prepare training for Kinzhal hypersonic missiles". Eurasia Daily Monitor. 13 May 2020. <https://jamestown.org/program/russiasaerospace-forces-prepare-training-for-kinzhal-hypersonic-missiles/> Accessed on 3 May 2020.

${ }^{161}$ Ibid.

${ }^{162}$ Sayler op. cit.

${ }^{163}$ McDermott op. cit.

${ }^{164}$ A Tate. "Scramjet test points to progress in China's hypersonic weapon development programme". Janes Defence Weekly 57/25. 2020. 6; A Tate. "Beijing's space

${ }^{165}$ Wilson op. cit. capabilities growing at a rapid pace". Janes Defence Weekly 57/25. 2020. 21.

${ }^{166}$ Center for Strategic and International Studies. "DF-17”. Missile Defense Project. 19 February 2020. $<$ https://missilethreat.csis.org/missile/df-17/> Accessed on 23 August 2020.

${ }^{167}$ Sayler op. cit.

${ }^{168} \mathrm{Ibid}$; AS Erickson. "China's massive military parade shows Beijing is a missile superpower". The National Interest. 1 October 2019. < https://nationalinterest.org/blog/buzz/chinasmassive-military-parade-shows-beijing-missile-superpower-84731> Accessed on 2 October 2019.

${ }^{169}$ Center for Strategic and International Studies. "DF-41". Missile Defense Project. 8 October 2019. <https://missilethreat.csis.org/missile/df-41/> Accessed on 23 August 2020.

${ }^{170}$ Tate, "Scramjet test ..." op. cit.

${ }^{171}$ Sayler op. cit.

172 Tate, "Scramjet test ..." op. cit.

${ }^{173}$ Ibid.

${ }^{174}$ Klare, “An 'arms race in speed'...” op. cit.

${ }^{175}$ MT Klare. "A strategy for reducing the escalatory dangers of emerging technologies". Arms Control Today. December 2020. <https:/www.armscontrol.org/act/2020-12/features/ strategy-reducing-escalatory-dangers-emerging-technologiesogies $>$ Accessed on 14 December 2020;

${ }^{176} \mathrm{KN}$ Waltz. "More may be better". In SD Sagan \& KN Waltz (eds), The spread of nuclear weapons: An enduring debate. New York, NY: WW Norton, 2013, 3-40.

${ }^{177}$ GH Snyder. Deterrence and defense: Towards a theory of national security. Princeton, NJ: Princeton University Press, 1961. 
${ }^{178}$ Nuclear weapons cannot and do not deter every conceivable threat to a state's security. They do not, for instance, deter attacks against states' minor interests; conversely, they serve to deter large-scale conventional and nuclear wars.

${ }^{179}$ Snyder op. cit.

${ }^{180}$ KN Waltz. "Nuclear myths and political realities". In KN Waltz (ed), Realism and international politics. New York, NY: Routledge, 2008, 276-293.

${ }^{181}$ Ibid.

${ }^{182}$ Waltz, "More may be better" op. cit.

${ }^{183}$ Ibid.

${ }^{184}$ Ibid.

${ }^{185}$ Ibid.

${ }^{186}$ Ibid.

${ }^{187}$ B Brodie. Escalation and the nuclear option. Princeton, NJ: Princeton University Press, 1966, 44.

${ }^{188}$ Ibid., p. 131.

${ }^{189}$ Waltz, "Nuclear myths and political realities" op. cit.

${ }^{190} \mathrm{Ibid}$.

${ }^{191}$ Ibid.

${ }^{192}$ Waltz, "More may be better" op. cit., p. 9.

${ }^{193} \mathrm{Ibid}$.

${ }^{194}$ Ibid., p. 26.

${ }^{195}$ Ibid.

${ }^{196}$ B Brodie (ed). The absolute weapon: Atomic power and world order. New Haven, CT: Yale Institute of International Studies, 1946.

${ }^{197}$ Waltz, "Nuclear myths and political realities" op. cit.

${ }^{198}$ TC Schelling. "Arms and influence". In TG Mahnken \& JA Maiolo (eds), Strategic studies: A reader. New York, NY: Routledge, 2008, 116.

${ }^{199}$ Waltz, "Nuclear myths and political realities" op. cit.; Brodie, The absolute weapon ... op. cit.

${ }^{200}$ Waltz, "Nuclear myths and political realities" op. cit.; Waltz, "More may be better" op. cit.

${ }^{201}$ AC Beyer. Kenneth Waltz's life and thought: An interview. Morrisville, NC: Lulu.

${ }^{202}$ SD Sagan. "The Korean missile crisis: Why deterrence is still the best option". Foreign Affairs 96/1. 2017. 72-82.

${ }^{203}$ Waltz, "More may be better" op. cit.

${ }^{204}$ Waltz, "Nuclear myths and political realities" op. cit.; Beyer op. cit.

${ }^{205}$ Brodie, The absolute weapon ... op. cit., p. 60.

${ }^{206}$ Waltz, "More may be better" op. cit.

${ }^{207}$ KN Waltz. "Waltz responds to Sagan". In Sagan \& Waltz op. cit., pp. 82-111.

${ }^{208}$ SD Sagan \& KN Waltz. "Indian and Pakistani nuclear weapons: For better or worse?" In Sagan \& Waltz, The spread of nuclear weapons op. cit., pp. 135-174.

${ }^{209} C f$. for instance SD Sagan. "Sagan responds to Waltz". In ibid., pp. 112-134; SD Sagan. "More will be worse". In ibid., pp. 41-81.

${ }^{210}$ Cf. KN Waltz. Theory of international politics. Boston, MA: McGraw-Hill, 1979.

${ }^{211}$ Waltz, "Waltz responds to Sagan" op. cit.

${ }^{212}$ Ibid.

${ }^{213}$ Waltz, "More may be better" op. cit., p. 89.

${ }^{214}$ Waltz, "Waltz responds to Sagan" op. cit.

${ }^{215}$ SD Sagan \& KN Waltz. "Is nuclear zero the best option?" In Sagan \& Waltz, The spread of nuclear weapons op. cit., pp. 215-228.

${ }^{216}$ Cf. R Jervis. "Review: Deterrence theory revisited". World Politics 31/2. 1979. 289-324.

${ }^{217}$ Cf. Sagan, "Sagan responds to Waltz" op. cit.; Sagan, "More will be worse" op. cit.; Krepinevich op. cit. 
${ }^{218}$ T Sauer \& R Thakur. "How many intensive care beds will a nuclear weapon explosion require?" Bulletin of the Atomic Scientists. 28 April 2020. $<$ https://thebulletin. org/2020/04/how-many-intensive-care-beds-will-a-nuclear-weapon-explosionrequire/> Accessed on 29 April 2020.

${ }^{219}$ Krepinevich op. cit., p. 71.

${ }^{220}$ Waltz, "Waltz responds to Sagan" op. cit., p. 110.

${ }^{221}$ Ibid.

${ }^{222}$ Ibid.

${ }^{223}$ Jervis op. cit., p. 299.

${ }^{224}$ Ibid.

${ }^{225}$ Ibid.

${ }^{226}$ Waltz, "Waltz responds to Sagan" op. cit.

${ }^{227}$ Waltz, "Nuclear myths and political realities" op. cit.

${ }^{228}$ Ibid,; p. 283.

${ }^{229}$ Ibid.

${ }^{230} \mathrm{H}$ Brown. Annual report, fiscal year 1981. Washington, DC: US Department of Defense, 1980.

${ }^{231}$ R Jervis \& M Rapp-Hooper. "Perception and misperception on the Korean Peninsula". Foreign Affairs May/June. 2018. 103-117.

${ }^{232}$ Waltz, "More may be better" op. cit.

${ }^{233}$ Waltz, "Waltz responds to Sagan" op. cit.

${ }^{234}$ Waltz, "More may be better" op. cit.

${ }^{235}$ Ibid.

${ }^{236}$ Ibid.

${ }^{237}$ Ibid.

${ }^{238}$ Ibid.

${ }^{239}$ Ibid.

${ }^{240}$ A Knight. "Kissinger critique". The Economist. 3 February 1979. <http://findit.library.yale. edu/catalog/digcoll:558495> Accessed on 28 February 2020.

${ }^{241}$ Ibid.

${ }^{242}$ Waltz, "Waltz responds to Sagan" op. cit.

${ }^{243}$ Waltz, "Nuclear myths and political realities" op. cit.

${ }^{244}$ B Brodie. "Nuclear weapons: Strategic or tactical?" Foreign Affairs 32/2. 1954. 217-229.

${ }^{245}$ Sagan \& Waltz, "Indian and Pakistani nuclear weapons ..." op. cit., p. 160.

${ }^{246}$ Waltz, "More may be better" op. cit.

${ }^{247}$ Waltz, "Waltz responds to Sagan" op. cit.

${ }^{248}$ Sagan \& Waltz, "Indian and Pakistani nuclear weapons ..." op. cit.

${ }^{249}$ Waltz, "Waltz responds to Sagan" op. cit., p. 100.

${ }^{250}$ Waltz, "Nuclear myths and political realities" op. cit., pp. 279-280.

${ }^{251}$ Waltz, "Waltz responds to Sagan" op. cit.

${ }^{252}$ Waltz, "Nuclear myths and political realities" op. cit.

${ }^{253}$ R Burns. "Saudi's couldn't stop oil attack, even with top US defences". ABC News. 19

September 2019. <https://abcnews.go.com/Politics/wireStory/saudis-stop-oil-attacktop-us-defenses-65703278> Accessed on 20 September 2019.

${ }^{254}$ Waltz, "Waltz responds to Sagan" op. cit., p. 103.

${ }^{255} \mathrm{Ibid}$.

${ }^{256}$ Ibid.

${ }^{257}$ Ibid.; Sagan \& Waltz, "Is nuclear zero the best option?" op. cit.

${ }^{258}$ A Kim. "US conducts successful ICBM intercept test". Arms Control Today. December 2020. $<$ https://www.armscontrol.org/act/2020-12/news-briefs/us-conducts-successful-icbmintercept-test $>$ Accessed on 4 December 2020.

${ }^{259}$ Ibid. 
${ }^{260}$ DG Kimball. "Missile defense and the arms race". Arms Control Today. December 2020. $<$ https://www.armscontrol.org/act/2020-12/focus/missile-defense-arms-race $>$ Accessed on 4 December 2020.

${ }^{261}$ Ibid.

${ }^{262}$ Waltz, "Nuclear myths and political realities" op. cit.; Waltz, "Waltz responds to Sagan" op. cit.; Sagan \& Waltz, "Is nuclear zero the best option?" op. cit.

${ }^{263}$ Waltz, "Waltz responds to Sagan" op. cit.

${ }^{264}$ D Axe. "Why Russia is angry at America's missile defense systems". The National Interest. 22 October 2019. < https://nationalinterest.org/blog/buzz/why-russia-angry-americasmissile-defense-systems-90111> Accessed on 23 October 2019.

${ }^{265}$ D Brown. "Russia just released videos of its next generation of nuclear weapons - here's what we know". Business Insider. 21 July 2018. <https://www.businessinsider.co.za/russiajust-released-videos-of-its-next-generation-of-nuclear-weapons-2018-7?r=US\&IR=T> Accessed on 22 July 2018.

${ }^{266}$ Y Kubovich. "Israel 'successfully tests' Arrow 3 missile defense system in Alaska". Haaretz. 28 July 2019. <https://www.haaretz.com/israel-news/israel-successfully-tests-arrow3-missile-defense-system-in-alaska-1.7580590> Accessed on 2 August 2019; SJ Freedberg. "New army laser could kill cruise missiles". Breaking Defense. 5 August 2019. <https://breakingdefense.com/2019/08/newest-army-laser-could-kill-cruisemissiles/> Accessed on 2 September 2019; SJ Freedberg. "LTAMDS: Raytheon to build linchpin of army air \& missile defense”. Breaking Defense. 17 October 2019. $<$ https://breakingdefense.com/2019/10/ltamds-raytheon-to-build-linchpin-of-army-airmissile-defense/> Accessed on 1 September 2019.

${ }^{267}$ Waltz, "More may be better" op. cit.

${ }^{268}$ Ibid.

${ }^{269}$ Wilson op. cit., p. 23.

${ }^{270}$ Waltz, "More may be better" op. cit., p. 7.

${ }^{271}$ Ibid., p. 8.

${ }^{272}$ Sagan \& Waltz, "Indian and Pakistani nuclear weapons ..." op. cit.

${ }^{273}$ Ibid.

${ }^{274}$ Ibid., pp. 168-169. 